\title{
ZERO RATING: A CASE FOR NET NEUTRALITY
}

\section{PIOTR ŁADNY}

University of Szczecin, Faculty of Management and Economics of Services, POLAND

e-mail: piotr.ladny@serviceinterlab.pl

\begin{tabular}{l|l}
$\begin{array}{l}\text { RECEIVED } \\
\text { ACCEPTED } \\
\text { JEL }\end{array}$ & $\begin{array}{l}\text { 18 January } 2018 \\
2 \text { September } 2018\end{array}$ \\
KEYSSIFICATION & L51, L86 \\
ABSTRACT & $\begin{array}{l}\text { The article presents the phenomenon of net neutrality and its impact on the development of the global telecom- } \\
\text { munications network, the Internet. It indicates examples of approaches related to the introduction of the open } \\
\text { network principle into the legal system and areas in which the implementation of this principle may face prob- } \\
\text { lems. The author characterised the zero rating phenomenon against the background of EU legal regulations and } \\
\text { indicated its potential threats to the open Internet and entities operating in the online ecosystem. }\end{array}$
\end{tabular}

\section{Introduction}

The global world, which is increasingly subject to integration processes, needs an efficient system that enables instant communication and access to information regardless of the physical location. The basis of this system is undoubtedly the Internet, which after only 28 years of operation has become the most important communication tool of the modern world. 
Network infrastructure and related information and communication technologies are often referred to as a nervous system that enables functioning and at the same time has an impact on almost every aspect of human life. The impact of the Internet on social and economic relations is so great that it is considered one of the basic tools for growth and social development, and the physical and economic accessibility of the global network and its services are currently one of the criteria for dividing the world into poor and the rich.

The growing importance of the global network is reflected in the increasing number of strategies, recommendations and regulations related to cyberspace, aiming at the most effective use of its potential.

Published in May 2010, The Digital Agenda for Europe (DAE), a plan for the development of the ICT sector (information and communication technologies) by 2020, is one of the seven pillars of the Europe 2020 strategy and is a formal confirmation of the growing importance of digital technologies in the modern world.

The DAE's amplification is the Digital Single Market Strategy, adopted by the European Commission in May 2015, which aims to remove barriers to development and access to modern services based on information technology by creating a single digital market in the EU.

The adoption of the National Broadband Plan by the Council of Ministers in January 2014 was an exemplification of the transfer of the European assumptions to the Polish market was. The NBP is a strategic document defining the activities and measures necessary to achieve the goal of ensuring universal broadband Internet access throughout the territory of the Republic of Poland.

\section{Net neutrality}

Implementation of the assumptions adopted in the strategies and plans, however, requires not only to solve technical and financial problems related to the construction of infrastructure but also to define the legal framework and principles on which all interested parties (network operators, service providers, individual and institutional clients and government agencies and institutions) will use the network infrastructure.

One of the fundamental principles determining the efficient functioning of an extremely complicated environment such as cyberspace is the neutrality of the network. According to this principle, all Internet users can access the network infrastructure and resources on an equal basis. Thanks to the principle of neutrality, every entity, regardless of the role, size and area in which it operates, has equal rights in the online ecosystem in the provision and use of services, and each type of content (information) is sent on the same principles. From a technical point of view, neutrality means the freedom of movement between any points of the network, without the interference of operators and discrimination of this traffic regarding its origin (from where), destination (where to) and the type of data transmitted (EDRi, 2013, pp. 5-6). Openness and neutrality of the network are considered a key element contributing to the development of innovative services, competition and the free flow of information. Civil organizations also point to the fact that compliance with this principle has a huge impact on the creation of new measures conducive to the exercise of citizens' rights, in particular in the area of freedom of expression and the right to receive and provide information.

Despite many arguments for ensuring the principle of neutrality, for many years this concept functioned as a postulate rather than a legal regulation. The very approach to neutrality in different countries is also significantly different.

This is clearly seen in the example of regulations adopted in the US and EU countries. In the case of the USA, in February 2015, the Federal Communications Commission, which supervised the market, adopted regulations 
that formally sanctioned the openness and neutrality of the Internet (FCC, 2015). However, in December 2017, the new FCC authorities repealed these regulations, supporting the arguments that the adopted provisions limit the freedom of ISPs in the provision of services and the use of business models (FCC, 2017). The new regulations enter into force on June 11, 2018 (Shepardson, 2018).

A completely different approach can be observed in European countries. In October 2015, the European Parliament adopted a package of telecommunication regulations, including the 2015/2120 (EU, 2015) regulation introducing legal protection for the openness of the Internet. In accordance with the provisions of the Regulation: "End-users shall have the right to access and distribute information and content, use and provide applications and services, and use terminal equipment of their choice, irrespective of the end-user's or provider's location or the location, origin or destination of the information, content, application or service, via their internet access service" Article 3(1) and „Providers of internet access services shall treat all traffic equally, when providing internet access services, without discrimination, restriction or interference, and irrespective of the sender and receiver, the content accessed or distributed, the applications or services used or provided, or the terminal equipment used" - Article 3(3).

In addition, due to emerging doubts about the content of the regulation, the Body of European Regulators for Electronic Communications (BEREC) has issued Guidelines to the National Regulatory Authorities (NRAs) on the implementation of the new net neutrality (BEREC, 2016).

The guidelines clarify many issues and indicate possible deviations from the principle of neutrality as well as the conditions under which they may be applied. The exceptions indicated concern 3 areas where, for technical, legal or business reasons, the principle of network openness may be limited or even suspended:

a) provision of specialist (special) services, i.e. services other than internet access services which are optimised for specific content, applications or services, or a combination thereof, where the optimisation is necessary in order to meet requirements of the content, applications or services for a specific level of quality;

b) traffic management, i.e. actions aimed at protecting the security and integrity of the network and enduser devices, such as blocking spam or attacks of the Denial of Services type, and preventing network congestion. Permissible traffic management also consists in blocking services whose provision is incompatible with EU or national law (e.g. related to infringement of copyrights or publication of paedophile material);

c) implementation of specific business models and commercial practices of ISPs, however, with the provison that "Agreements between providers of internet access services and end-users on commercial and technical conditions and the characteristics of internet access services such as price, data volumes or speed, and any commercial practices conducted by providers of internet access services, shall not limit the exercise of the rights of end-users laid down in Article 3(1)".

\section{Zero rating offers}

From the point of view of NRAs, which were required to monitor and enforce the principles of an open and neutral internet, particularly interesting and also difficult seem to be problems concerning the third group of exemptions. An example is the transfer limits (data cap) used in ISPs offers, where after the limit has been exhausted, the operator reduces the transmission speed or charges higher fees (or requires the purchase of an additional package). Such solutions do not raise any doubts as long as the restrictions apply equally to all services 
used by end-users. Problems arise, however, when the ISP, wanting to increase the attractiveness of its offer, introduces services that are excluded from the limits set for users. Such solutions are mainly introduced by mobile operators BEREC, 2012), and because the traffic generated by the user for these services or content is handled by the ISP without additional payment, such offers are referred to as zero rating.

From the information presented in Report on the implementation of Regulation (EU) 2015/2120 and BEREC Net Neutrality Guidelines (BEREC, 2017), it appears that regulatory authorities confirmed the use of zero-rating offers regarding one or more types of content or services in as many as 25 out of 30 countries (28 EU countries and Norway and Iceland).

In practice, there may be many variants of zero rating offers, and the basis for their distinction is, among others:

1. Paid or free inclusion of a given service or content in a zero rating offer. An ISP may offer unlimited access to specific content to customers without charging a fee from their provider or make the inclusion of content in a zero rating offer subject to a fee paid by the provider (Eisenach, 2015, p. 2).

2. Commercial or non-commercial purpose of the business. The types of zero rating offer may depend on whether the content covered by them is made available by the content provider for profit (e.g. commercial VOD service) or non-profit (Wikipedia). However, the problem may be precisely defining the commercial nature of the service if its provider derives profits indirectly, e.g. from displayed advertisements, from collected and shared for a fee information about end-users or from additional paid services recommended by the provider.

3. Guaranteeing exclusivity. Exclusivity can occur in 2 variants. First of all, it may refer to offering the internet content of a specific provider on a zero-rating basis only by one ISP. In agreements of this type, the content provider usually receives payments from an ISP. In the second option, exclusivity may consist in the ISP'S commitment not to conclude zero-rating agreements with competitors of the entity offering specific internet content. In this case, it is usually the content provider that pays to the ISP.

4. Type of content. The zero rating offer may apply to a specific provider or a whole specific category of web content (e.g., any type of music streaming). In practice, providing end users with unlimited access to specific content is complicated and extremely rare for technical and organizational reasons. In the case of the Music Freedom (music streaming), the service offered in the USA by the T-mobile, despite the operator's declaration that access to the service is open to all content providers, in practice - due to technical conditions, among other things - only 40 out of 2000 legally operating online music providers in the USA use it (van Schewick, 2016, p. 18).

5. The durability of agreement between the content provider and the ISP. Such an agreement may be permanent or transitory. In the latter case, the agreement is concluded for a strictly defined time and applies, for example, during the promotion period (IGF, 2014).

6. Other detailed conditions, such as the provisions of the regulations for the provision of services to end users. An example is the determination by the ISP of the conditions under which it is possible to use an unlimited access to the content of the service or application after the data limit has been reached.

The assessment of the impact of zero rating offers on the openness of the Internet and the admissibility of their use is difficult not only due to the multitude of variants in which they are implemented by the ISP. The problem is 
also the fact that the effects it causes for content providers, ISPs and end users are ambiguous and often assessed in an extreme way.

It seems that it is ISPs that benefit most from applying zero rating offers. This thesis is confirmed by the previously mentioned popularity of such offers in Europe (Berec, 2017, pp. 7-10). Supporters of the zero-rating stress that it can positively affect competition between ISPs, allowing them to differentiate the offer and specialize in providing services of a certain type (Peng, Preta, 2015, p. 7). Therefore, it positively influences the process of building a competitive ISPs market.

For users, the zero rating offer may be a remedy for low data limits, particularly severe in countries with poorly developed mobile infrastructure (developing countries). On the other hand, the effect of the development of zerorating offers, i.e. the privileged treatment of selected content, services or applications, may be a deterioration of the position of suppliers whose content is not available in unlimited packages. In the opinion of Tim BernersLee, one of the creators of technology enabling the functioning of the Internet, net neutrality is not only harmed by blocking and slowing down access to specific content, services or applications, but also by the so-called positive discrimination, such as when an ISP favours one of the content providers (Berners-Lee, 2015). Similar conclusions, indicating that favouring the selected content by the ISP may harm competition and innovation among its suppliers, result from consultations regarding open internet, conducted by the European Commission (UE, 2010, p. 2).

The zero rating offers have the largest impact on the market situation in the area of content providers. In relation to large entities offering popular services and content or new players who can afford to pay fees enabling the introduction of content to unlimited offers of mobile operators, the use of zero rating will undoubtedly foster the strengthening of the market position. However, for new players, providers of content targeted at small groups of recipients or local (national or regional) markets, the technical or financial requirements of zero-rating may lead to deterioration. The consequence will be the systematic strengthening of the position of large players while weakening small and new, leading to the monopolization of the market.

The use of zero-rating for services or content provided on non-commercial terms seems to be the least controversial. As part of the Wikipedia Zero project, agreements between Wikimedia Foundation Inc. and ISPs are concluded without remuneration and with no reservations as to exclusivity. The sites offered in this way do not display ads, and the foundation itself is maintained with donations. The social benefits associated with the creation and sharing of knowledge resources on special terms encourage recognition of the admissibility of such exceptions.

Despite the fact that in strictly defined situations (content made available non-commercially, temporary agreements) zero-rating may not cause negative effects or may have positive effects for selected groups, the majority of arguments suggest that in the long term and with regard to the entire telecommunications market the negative effects will prevail. It is also worth emphasizing that the negative effects associated with the zero-rating are hardly noticeable by end users. This is confirmed by the analyzes carried out by BEREC, according to which, when choosing variants of services offered by the ISP, consumers do not take into account long-term effects relating to innovation and competition. Therefore, these values should be protected by the regulator (BEREC, 2015, p. 20). A similar objective was formulated in the general assumptions to Regulation $2015 / 2120$, where it was pointed out that "This Regulation aims to establish common rules to safeguard equal and non-discriminatory treatment of traffic in the provision of internet access services and related end-users' rights. It aims to protect end-users and simultaneously to guarantee the continued functioning of the internet ecosystem as an engine of innovation". 


\section{Conclusions}

Net neutrality and open and unrestricted access are the rules that have been connected to the Internet since its inception. The need to maintain these principles and cover them with legal protection was repeatedly mentioned in their public statements by Vinton Cerf, considered one of the "fathers" of the Internet, co-creator of the TCP/IP protocol, Tim Berners-Lee, creator and one of the pioneers of the WWW service, Viviane Reding, Vice-President of the European Commission, and Neelie Kroes, Vice-President of the European Commission and European Commissioner for the Digital Agenda.

Introduced by virtue of Regulation (EU) 2015/2120 of The European Parliament and of The Council as well as BEREC Guidelines on the Implementation of the National Net Neutrality Rules, regulations and recommendations sanctioned the legal protection of these principles in EU countries. However, as the internet ecosystem is currently an extremely complex mechanism both from the technical and organizational side, the regulations introduced will certainly not be able to solve all problems related to the non-observance or circumvention of the network neutrality principles by ISPs. Already the growing popularity of zero rating offers, their various variants and possible combinations introduced by ISPs are a challenge and a problem from the point of view of their impact assessment. NRAs which in the light of adopted regulations have gained competence to evaluate ISPs activities, including the use of zero rating offers in terms of compliance with the principles of open internet access and net neutrality must develop precise and non-discriminatory principles that will form the basis for possible intervention in the market. Since no comprehensive studies to assess the impact of zero-rating on competition among content, service and application providers have been conducted so far (Adams, Stallman, 2016, p. 24), defining the areas and rules for NRAs requires further research and analysis at EU and national markets level.

\section{References}

Adams, R.S., Stallman, E. (2016). Zero Rating: A Framework for Assessing Benefits and Harms. Retrieved from: https://cdt.org/ files/2016/01/CDT-Zero-Rating_Benefits-Harms5.pdf.

BEREC (2012). BEREC Guidelines for quality of service in the scope of net neutrality. Retrieved from: http://berec.europa.eu/eng/ document_register/subject_matter/berec/download/0/1101-berec-guidelines-for-quality-of-service-_0.pdf.

BEREC (2016). BEREC Guidelines on the Implementation by National Regulators of European Net Neutrality Rules. Retrieved from: https://berec.europa.eu/eng/document_register/subject_matter/berec/regulatory_best_practices/guidelines/6160-berecguidelines-on-the-implementation-by-national-regulators-of-european-net-neutrality-rules.

BEREC (2017). Report on the implementation of Regulation (EU) 2015/2120 and BEREC Net Neutrality Guidelines. Retrieved from: https://berec.europa.eu/eng/document_register/subject_matter/berec/reports/7529-berec-report-on-the-implementationof-regulation-eu-20152120-and-berec-net-neutrality-guidelines.

Berners-Lee, T. (2015). Net neutrality is critical for Europe's future. Retrieved from: https://ec.europa.eu/commission/commissioners/ 2014-2019/ansip/blog/guest-blog-sir-tim-berners-lee-founding-director-world-wide-web-foundation_en.

EDRi (2013). Net neutrality. The EDRi papers, 8. Retrieved from: https://edri.org/papers/net-neutrality.

Eisenach, J.A. (2015). The Economics of Zero Rating. Retrieved from: www.nera.com/content/dam/nera/publications/2015/Economicsof ZeroRating.pdf.

EU (2015). Regulation 2015/2120 of the European Parliament and of the Council of 25 November 2015 laying down measures concerning open internet access and amending Directive 2002/22/EC on universal service and users' rights relating to electronic communications networks and services and Regulation (EU) No 531/2012 on roaming on public mobile communications networks within the Union. Retrieved from: https://eur-lex.europa.eu/legal-content/EN/TXT/HTML/?uri=CELEX:32015R2120\&from=PL.

FCC (2015). FCC Adopts Strong, Sustainable Rules to Protect the Open Internet. Retrieved from: https://www.fcc.gov/document/ fcc-adopts-strong-sustainable-rules-protect-open-internet. 
FCC (2017). FCC Releases Restoring Internet Freedom Order. Retrieved from: https://www.fcc.gov/document/fcc-releasesrestoring-internet-freedom-order.

IGF (2014). Net Neutrality, Zero-Rating \& Development: What's the Data? Retrieved from: https://www.intgovforum.org/multilingual/ content/finished-2014-09-03-ws208-net-neutrality-zero-rating-and-development-whats-the-data-room-5.

Peng, P., Preta, A. (2015). Discrimination and Neutrality on the Internet: the Zero Rating Case. Retrieved from: www.dimt.it/wp-content/ uploads/2015/10/Zero-rating_vienna_review.pdf.

Shepardson, D. (2018). U.S. 'net neutrality' rules will expire on June 11: FCC. Retrieved from: https://www.reuters.com/article/us-usainternet/u-s-net-neutrality-rules-will-end-on-june-11-fcc-idUSKBN1IB1UN.

Van Schewick, B. (2016). T-Mobile's Binge on Violates Key Net Neutrality Principles. Retrieved from: https://cyberlaw.stanford.edu/ downloads/vanSchewick-2016-Binge-On-Report.pdf.

Cite this article aS: Ładny, P. (2018). Zero rating: A Case for net neutrality. European Journal of Service Management, 3 (27/2), $245-251$. DOI: 10.18276/ejsm.2018.27/2-30. 